\title{
LA MONARQUía \\ Y LA CONSTITUCIÓN DE 1978
}

SABINO FERNÁNDEZ CAMPO

Ex-Jefe de la Casa de S. M. el Rey 


\section{LA MONARQUÍA Y LA CONSTITUCIÓN DE 1978}

POR

\section{SABINO FERNÁNDEZ CAMPO}

Ex-Jefe de la Casa de S. M. el Rey

La Monarquía ha sido, a mi juicio, una pieza clave en el reciente período de la transición política española.

$\mathrm{Ha}$ de reconocerse tambien que su restablecimiento, despues de la muerte de Franco pero preparado desde mucho antes, tuvo algo de extraordinario e incluso de prodigioso, puesto que vino a ser quizá el único de los extremos que el vencedor de la guerra civil dejó «atado $y$ bien atado».

Si es evidente la secular tradición monárquica de España, tambien lo es que en los tiempos inmediatamente anteriores al 14 de abril de 1931, la institución venía deteriorándose y adquirían cada vez mas vigor las tendencias republicanas. Aparte de otras variadas causas de descontento, algunas de las cuales se remontaban ya a la guerra de Marruecos, las circunstancias derivadas de la Dictadura del General Primo de Rivera constituyeron la culminación de un lento e ininterrumpido proceso de descrédito.

Con la renuncia al trono de Don Alfonso XIII y la proclamación de la República, consecuencia anormal de unas elecciones municipales, se inicia un nuevo régimen que hasta cierto punto sorprendió incluso a quienes súbitamente se hicieron cargo de un poder desmoronado. Pero los acontecimientos se venían venir.

La frase del Almirante Aznar, "España se acostó monárquica y se levantó republicana", puede ser simbólica, pero no exacta. La evolución fue mas prolongada. 
Es triste leer ahora, pasados los años, el mensaje de despedida del Rey, y estremece un poco recordar el largo debate de las Cortes republicanas que dio lugar al acta de acusación contra aquél. La valiente, pero significativamente aislada, defensa del Conde de Romanones, no pudo evitar la sentencia de culpabilidad contra el Monarca, redactada en los términos mas duros y vejatorios.

Podía tener razón Cambó cuando decía que "las Monarquias no caen por los ataques de los republicanos, sino por sus propios errores». Pero la misma frase puede ser aplicada después a la República.

Las equivocaciones de sus hombres y su sectarismo en algunos aspectos, como el religioso o el militar, si bien provocaron múltiples rechazos, no hicieron, sin embargo, evocar con convicción el retorno de la Monarquía, que cayó en un olvido sólo roto tímidamente por reducidos grupos de fieles partidarios, pues en realidad los grandes partidos de la derecha procuraron incluirse en el nuevo sistema establecido, que muchos sectores veían con esperanza.

El cambio de régimen permitió una mayor decisión y radicalidad en las medidas. Pero el entonces Ministro de la Guerra fue mas rotundo e hiriente en sus palabras que en sus obras. La referencia que hizo públicamente a la "trituración» del Ejército, dejó una huella imborrable que constituyó la causa de muchos acontecimientos posteriores, si bien la reorganización militar era indispensable.

El General Sanjurjo, que en abril de 1931, siendo Director General de la Guardia Civil, no garantizó la defensa de la Monarquía, se sublevó en Sevilla el 10 de agosto de 1932. Pero su intento fue mas bien una manifestación testimonial de rechazo a la República que de entusiasta resurgimiento monárquico. $\mathrm{Y}$, en todo caso, carecia previamente de un respaldo importante.

Durante la celebración del Consejo de Guerra, no sé si el Fiscal o el Presidente del tribunal, preguntó a Sanjurjo:

- "¿Y con quién contaba Vd. para la sublevación?".

- "Si hubiera triunfado, con todos, incluido Vd. Como he fracasado, con nadie», fue la respuesta del General.

Cuando el golpe de Estado militar del 18 de julio de 1936 se convirtió en una cruenta y prolongada guerra civil, se despertaron algunas esperanzas monárquicas, pero la duración de la contienda centró la atención, por parte de cada bando, en vencer al adversario, mas que en pensar en futuras fórmulas políticas definitivas, si bien fueron notables 
las influencias respectivas de los sistemas totalitarios de Berlin y Roma, por un lado, y Moscú por otro.

No puede, pues, decirse que la guerra civil española se produjo con el fin de restaurar la Monarquía; pero tambien es indudable que sin la guerra civil española y el triunfo de las fuerzas de Franco, la Monarquía no hubiera tenido demasiadas posibilidades de volver a instaurarse en nuestro país, donde sólo quedaban reminiscencias nostálgicas.

La Ley de Sucesión de 1947, la Orgánica del Estado de 1966 y la de 1969 por la que se designa sucesor a título de Rey a Don Juan Carlos de Borbón, van marcando claramente el retorno a la Monarquía, en el ámbito de una transición que, en frase de Torcuato Fernández Miranda, habia de realizarse "desde la Ley a la Ley, a través de la Ley".

Una de las personas que contribuyeron con tesón a la aplicación práctica de las disposiciones legales, Laureano López Rodó, describe en su esclarecedor libro La larga marcha hacia la Monarquía, el camino seguido y los esfuerzos realizados a tal fin.

En 1975, a la muerte de Franco, el Príncipe de España es elevado al Trono y la Constitución de 1978, aprobada en referendum, reafirma la Institución incluida en el texto fundamental.

Pero, ¿cómo se habia conseguido ese resultado?

Lo cierto es que no se aprovecharon las circunstancias para establecer la Monarquía, sino que se confiaba en la Monarquía para condicionar las circunstancias.

Al fin y al cabo, en el posfranquismo la legalidad era monárquica y los partidarios de aquel régimen fundaban la esperanza en la conservación de sus instituciones a través del reinado de Don Juan Carlos, de la misma manera que los deseosos de las reformas confiaban que tambien por medio del nuevo Rey se estableciera un sistema democrático.

Como dijo en uno de sus libros José María de Areilza, "el Rey era la clave del arco de la operación que se iba definiendo en el horizonte. Don Juan Carlos se iba afianzando como una última y definitiva referencia arbitral y suprema en cuya persona se anudaban las diversas posibilidades que se ofrecían para lograr un consenso lo mas amplio posible que hiciera viable el entendimiento constitucionalı.

La figura del Rey, con su básica formación militar, constituía tambien una especial seguridad con respecto a su relación con las Fuerzas 
Armadas, al fin y al cabo un factor muy importante a tener en cuenta en aquellos momentos, para conseguir una transición política amparada por ellas y evitar que constituyeran un poder efectivo proclive a mantener situaciones pasadas.

El último mensaje del General Franco al pedir a los españoles que rodearan al futuro Rey de España, Don Juan Carlos de Borbón, del mismo afecto y lealtad que a él le habían prestado, tenía su continuidad en la primera alocución de S.M. el 22 de noviembre de 1975, cuando afirmaba textualmente: "Como primer soldado de la Nación, me dedicaré con ahínco a que las Fuerzas Armadas de España, ejemplo de patriotismo y disciplina, tengan la eficacia y la potencia que requiere nuestro pueblo».

En estas circunstancias, sin embargo, las izquierdas se manifestaban claramente republicanas y habian olvidado ya los compromisos concertados con Don Juan de Borbón a finales de los años $\mathbf{4 0 .}$

La situación era delicada y por eso resultó tan satisfactorio que se afrontara con prudencia. Los cambios demasiado radicales engendran siempre más desgracias que las que pretenden erradicar. Permanecía vivo el recuerdo de una lamentable guerra civil y el temor de que pudieran renovarse los enfrentamientos violentos. Había que evitar la ruptura - aunque algunos la propugnaran - y en la democratización pacífica y civilizada resultaba imprescindible contar con la Corona, que podía convertirse en lo que despues se denominó "motor del cambio".

De lo acontecido en aquel período y en el camino de la elaboración de la norma constitucional, resulta de interés recordar el discurso que el Grupo Parlamentario Socialista del Congreso elaboró para mantener su voto particular al párrafo $3 .^{\circ}$ del artículo $1 .^{\circ}$ del Anteproyecto de Constitución, y que leyó el Sr. Gómez Llorente ante la Comisión de Asuntos Constitucionales. Se trataba de una cuidadosamente construida exposición en favor de la República, que contenía razonamientos precisamente opuestos a las ventajas de permanencia, continuidad y automatismo de la sucesión que constituyen tradicionalmente algunos de los argumentos mas sólidos en favor del sistema monárquico.

Este voto particular que se convirtió en testimonial, no tenía posibilidades políticas de prosperar, pero fue el símbolo de una actitud que contribuyó a determinar y limitar las facultades de la Corona y a que el Rey hubiera de moverse en unos niveles muy reducidos de poder político efectivo (potestas) aunque, desde luego, suficientes para ejercer con la máxima dignidad e influencia (auctoritas) su alta misión. 
"Del principio de la soberanía popular en sus más lógicas consecuencias, en su más pura aplicación - decía el Sr. Gómez Llorente en su intervención - se infiere que toda magistratura deriva del mandato popular; que las magistraturas representativas sean fruto de la elección libre, expresa, y por tiempo definido y limitado".

Y continuaba asi: "La limitación, no sólo en las funciones, sino en el tiempo de ejercicio de los magistrados que gobiernan o representan a la comunidad, constituye una de las ventajas mas positivas de los sistemas democráticos, pues permite resolver en forma pacífica, gracias a la prevista renovación periódica, el problema de la sustitución de las personas que encarnan dichos cargos, volviéndose, por el contrario, sumamente conflictivos el desplazamiento y sustitución de los gobernantes, tantas veces necesario en la vida de los pueblos, cuando no existe como procedimiento ordinario el régimen de elección periódica».

"Las magistraturas vitalicias, y aún mas las hereditarias, dificultan el fácil acomodo de las personas que ejercen cargos de esa naturaleza a la voluntad del pueblo en cada momento histórico. No se diga para contrarrestar este argumento que pueden existir mecanismos en la propia Constitución que permitan alterar estas estructuras, pues resulta obvio que tales cambios llevan consigo un nivel de conflictividad inconmensurablemente mayor que la mera elección y reelección".

"Renovar a los gobernantes, incluso aquéllos que ejerzan las mas altas magistraturas, es necesario, $y$ aún a veces imprescindible, $y$ no sólo porque la voluntad del pueblo sea mudadiza caprichosamente, sino porque la manera objetiva cambia; o la persona misma, dejando de ser lo que era, o las circunstancias que la hicieron la más idónea en un momento dado, o simplemente ambas cosas de consuno, surgiendo otras posibilidxades óptimas».

"Por otra parte, es un axioma que ningún demócrata puede negar la afirmación de que ninguna generación puede comprometer la voluntad de las generaciones sucesivas. Nosotros agregaríamos -sigue diciendo el orador socialista - que se debe incluso facilitar la libre determinación de las generaciones venideras."

Pero después de estas manifestaciones, cuyas comillas acabo de cerrar, y de muchas otras contenidas en el extenso discurso donde se expone la postura del Partido Socialista, su representante termina diciendo:

"Finalmente, señoras y señores diputados, una afirmación que es un serio compromiso. Nosotros aceptamos como válido lo que re- 
sulte en este punto del Parlamento constituyente. No vamos a cuestionar el conjunto de la Constitución por esto. Acatamos democráticamente la ley de la mayoría. Si democráticamente se establece la Monarquía, en tanto sea constitucional, nos consideramos compatibles con ella».

Asi que en definitiva - como decía Óscar Alzaga - , se venía a vislumbrar una posición socialista de apoyo condicionado a la Monarquía, estableciendo de este modo una clara distancia respecto a la idea tradicional de la lealtad monárquica.

Se ha dicho, con razón, que la Corona fue un arma de negociación de todos, en uno u otro sentido. Como afirma José Manuel Otero en su libro Nuestra democracia puede morir, una de las labores mas importantes en aquellos tiempos de la transición fue la de convencer a las fuerzas políticas entonces surgidas a la vida pública para que legalizaran sin cuestionar a la Monarquía, en la cual podría apoyarse la democracia. A su vez, aquellas fuerzas negociaron el obtener su reconocimiento oficial aportando la admisión de la Corona.

Las cesiones fueron recíprocas, pero precisamente ese consenso pacífico, ese juego de los intercambios y los intentos de contentar a todas las partes, hicieron que las soluciones fueran en algunos aspectos, y singularmente en el de la Monarquía, un tanto ambiguas e indeterminadas, sin que pudiera llegarse siempre a resultados concretos. De ahí derivan, sin duda, algunas incertidumbres que hemos de dar por aceptables y satisfactorias, puesto que contribuyeron en aquellos momentos a dar salida a una situación delicada y compleja.

El propio Franco había advertido con frecuencia al Príncipe de España, en las ocasiones en que éste le solicitaba información, consejo o indicaciones políticas: "Cuando Vuestra Alteza ocupe el Trono, todo se desarrollará de manera diferente».

$Y$ diferente hubo de ser el desarrollo.

Pero se incluyó a la Monarquía en la Constitución, en virtud del acuerdo producido por encima de las tendencias republicanas de algunos, de la desconfianza de otros y con las esperanzas de todos. $Y$ así, en el número tres del artículo $1 .^{\circ}$ se proclama: mentaria».

"La forma política del Estado español es la Monarquía parla-

Con acierto y sutileza se consiguió superar la cuestión de si la Monarquía se restauraba o se instauraba. La opción restauradora podía significar un repudio del pasado, tanto franquista como republica- 
no. La instauración suponía privar a la Corona de uno de sus valores fundamentales, que es la continuidad. Se adoptó una fórmula que responde tambien al carácter transacional y ambiguo que inspiró la Constitución en algunos aspectos: "La Corona de España es hereditaria en los sucesores de S.M. Don Juan Carlos I de Borbón, legítimo heredero de la dinastía histórican.

Pero, ¿qué es la Monarquía parlamentaria?

No me atrevo a decir rotundamente que sean antagónicos los conceptos "Monarquía" y "parlamentaria». Pero en todo caso es un sistema que ofrece dificultades de acomodación y exige un tacto extraordinario para que los dos términos puedan armonizarse.

La Monarquía Parlamentaria es el resultado histórico de un proceso que condujo desde el siglo XVIII a la racionalización de la forma política monárquica y a su conciliación con el principio democrático. Por ello es preciso hacerse una pregunta delicada: ¿Existe todavía Monarquía cuando ésta ha de integrarse en un sistema constitucional, en el cual el principio democrático fundamenta el Estado, inspira su organización y es el único que legitima el poder a través de ella?

No repetiré opiniones de diversos autores que en otro momento ya recogí sobre este compromiso impuesto por las relaciones políticas reales entre la Corona y el Parlamento, pero sí expresaré que el sistema supone una limitación de las facultades del Rey, como último intento de basar la unidad estatal sobre el principio monárquico.

Este tipo de sistema político, que precisamente se ha denominado "Monarquía limitada», es el establecido en nuestra Constitución de 1978.

Ya he hecho referencia a las transacciones en las cuales la Monarquía vino a constitituir una especie de "moneda de cambio» para compensar cesiones o conseguir acuerdos en la redacción de esa Constitución hoy vigente.

Por otra parte, nunca hubiera sido posible, a estas alturas, establecer una Monarquía anacrónica, que estuviera en oposición con las corrientes evolutivas de esta institución. El proceso de transformación de las Monarquías inicialmente absolutas en Monarquías constitucionales limitadas y después en auténticas Monarquias parlamentarias, se había roto en España. De esta forma, nuestra Constitución se vio en la necesidad de formular ex novo, mediante los preceptos correspondientes de una norma escrita, lo que se entiende por Monarquía parlamentaria. 
Tenia toda la razón el Profesor Sánchez Agesta al escribir que el proyecto revelaba claramente un propósito de racionalizar el régimen parlamentario, expresando en Derecho escrito lo que ha sido el resultado de un proceso evolutivo y consuetudinario en las monarquías europeas, que han establecido en el cuadro de una Monarquía constitucional y democrática el régimen parlamentario.

El mismo autor prosigue diciendo que «esta racionalización quita a este régimen una de sus grandes virtudes, la flexibilidad en la relación del juego de poderes, $y$ ha hecho que al fijar en preceptos los caracteres de este régimen se olviden prerrogativas cuya omisión puede significar un grave entorpecimiento en el funcionamiento de las Instituciones".

Sin embargo, como reconoce Óscar Alzaga, ello no es debido a una desorientación técnica por parte de quienes han intervenido en la redacción de la Constitución, sino corolario obligado del juego de fuerzas a que antes hice referencia $y$, muy en especial, al interés en soslayar la polémica sobre la forma republicana de Gobierno, y restaurar una Monarquía cuyo abanico de competencias políticas es reducido, pero que ofrece las características precisas para llegar a ser efectivamente una Monarquía con gran arraigo $y$, en suma, la Monarquía de todos los españoles.

En el proceso de elaboración de la Constitución española de 1978, y como miembro de la Casa de S.M. el Rey, me correspondió mantener diversas reuniones con el entonces Presidente de las Cortes

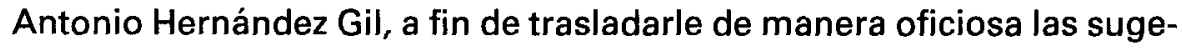
rencias que pudieran considerarse oportunas en cuanto a las facultades del Monarca que habrían de incluirse en nuestra Ley fundamental.

Los cambios de impresiones fueron numerosos y sinceros, pero las deliberaciones y los trabajos de la Comisión correspondiente eran ya lo suficientemente delicados para pretender que aquellos cometidos fueran destacados y numerosos en el esquema de una Monarquía parlamentaria, y hasta cabía pensar en el peligro de conseguirlo, pues podrían convertirse en un arma de dos filos. Si las funciones reales son muchas e importantes, la complejidad de cumplirlas en todo momento y acertadamente, se combinaba con la posible crítica por abstenerse de hacerlo.

Recuerdo, sin embargo, cómo se pensó en cuatro puntos concretos, que resumiré de pasada: 
- La previsión de un trámite - semejante, por ejemplo, al establecido en la Constitución de 1812, pero acomodado a los tiempos actuales - para el supuesto de que el Rey desintiera abiertamente de una disposición legal sometida a su sanción, sin convertir siempre a ésta en un acto mecánico y obligado.

- La posibilidad de que el Rey tomara la iniciativa para convocar un referendum sobre temas trascendentales para la $\mathrm{Na}$ ción, que se plantearan de forma imprevisible, por encima de los programas, las promesas y los acuerdos de los partidos políticos.

- La facultad del Rey de dirigirse a los españoles mediante mensajes especiales, en ocasiones muy determinadas.

- La creación de un Consejo Real que pudiera asesorar a S.M. en caso necesario.

Sin embargo, ni las circunstancias eran propicias ni el interés decisivo.

Se llegó, pues, a la regulación de las funciones reales que se incluyen en la Constitución vigente. Entre los condicionamientos que afectan al sistema de Monarquía parlamentaria y las condiciones en que aquélla se elaboró para superar posiciones opuestas y armonizarlas, las facultades del Rey aparecen reducidas y limitadas.

No voy a analizarlas ahora con detalle. Me limitaré a agruparlas en cuatro grandes bloques, a mi juicio bien diferenciados, pero relacionados entre sí, para llegar a unas conclusiones tan personales como sencillas y vulgares o tal vez vulgares y sencillas por ser personales.

- En el primer grupo podrían considerarse las funciones simbólicas y representativas del número 1 del artículo 56 de la Constitución, pues «el Rey es el Jefe del Estado, símbolo de su unidad y permanencia" y "asume la mas alta representación del Estado en las relaciones internacionales, especialmente con las naciones de su comunidad histórica".

- Al segundo grupo pertenece la facultad incluida en el mismo número y artículos citados: "Arbitra y modera el funcionamiento regular de las instituciones». 
Asimismo, pudiera pertenecer a este grupo la amplia obligación, que tiene al mismo tiempo la faceta de trascendente función, deducida de la fórmula del juramento del Rey ante las Cortes Generales, recogida en el artículo 61: "Guardar la Constitución y las Leyes".

- Funciones ejecutivas son las reseñadas en los diversos apartados del artículo 62, siempre condicionadas por propuestas o regulaciones específicas y con la necesidad del preceptivo refrendo.

- Finalmente, estarían las facultades del artículo 65, de cuyos dos apartados se deduce la libertad del Rey en cuanto a la distribución de la cantidad global fijada por las Cortes para el sostenimiento de su Familia y Casa, así como el nombramiento y relevo de los miembros civiles y militares de su Casa.

Al llegar a este punto, podriamos hacernos una pregunta: ¿Sería conveniente revisar las facultades del Rey previstas en la vigente Constitución para ampliarlas, modificarlas o definirlas mejor?

Pensemos, ante todo, que siempre es muy delicado introducir innovaciones en los textos fundamentales, cuando no vienen obligadas por una necesidad ineludible.

En segundo lugar, hemos de considerar que la Institución, en su nueva fase, a partir de la elevación al Trono de S.M. Don Juan Carlos I y con arreglo a la Constitución en vigor ha venido funcionando de una manera correcta, sin complicaciones ni problemas notables, sino consolidándose día a día con naturalidad e insertándose en la vida nacional de manera creciente. Cuando las cosas marchan bien y el funcionamiento no ofrece entorpecimientos graves, es preferible no tocarlas.

Finalmente, por lo que se refiere a la Corona, en la propia Constitución están las bases que permiten desarrollarla en algunos aspectos, si fuera necesario, como se prevé en el número 5 del artículo 57 con respecto a la sucesión.

Es cierto que pudiera haber algunos extremos dudosos o poco definidos que, en todo caso, sería posible llenar con unas costumbres, unos hábitos o unos procedimientos que fueran constituyendo una tradición o un estilo; pero nada de esto afectaría a las atribuciones regla- 
das que a S.M. el Rey encomiendan los distintos apartados del artículo 62 de la Constitución y que he clasificado como funciones ejecutivas.

Y nada hay que objetar a las del artículo 65, tal vez las únicas en que tiene intervención la voluntad del Monarca.

Pero se ha hablado y escrito mucho sobre ese poder moderador que corresponde al Rey, junto con el de velar por el funcionamiento regular de las instituciones, y que hemos incluido en el apartado primero. Un poder tan poco definido como importante $y$ tal vez tan importante por poco definido.

Muchas veces he recordado las opiniones de Antonio Hernández Gil en su libro "El cambio político español y la Constitución" al responder a algunas de las imputaciones que a su texto se hacen.

"¿Premeditamente ambigua»? Bien. ¿Pero qué quiere decirse con ambigüedad? ¿Su único sentido posible es el peyorativo? No. Por una parte, característica definitoria de las normas jurídicas, de las leyes -y con mas razón de las Constituciones - es la de ser generales. Ahí radica su poder de comprensión, su resistencia al tiempo. El supraderecho de los principios, de tanta fertilidad en la aplicación, tiene por base la generalidad de sus enunciados. "¿Hasta dónde llega la generalidad como requisito de la norma y dónde empieza la ambigüedad»?, termina preguntando el que fue Presidente de las Cortes.

En la Constitución de 1978, la Corona, a la vez que quedaba marcada por la cota mas baja de poder, lograba un "status" de irresponsabilidad política $y$, con frecuencia, el nivel mas alto de autoridad. El rey se convierte así en lo que Benjamín Constant denominó el «poder neutro", a la vez que pierde la posibilidad de hacer prevalecer por la fuerza del Derecho sus puntos de vista particulares sobre la opinión de sus ministros, pero le queda siempre la vía de la persuasión.

Como advirtió Bahegot, el gran teórico de la Monarquía británica, "el poder regio tiene en cierta manera que quedar velado, como una prerrogativa secreta, porque la Monarquía contiene un elemento emocional y mágico y el misterio de la magia no puede realizarse a la luz del día".

Por lo tanto, tal vez la mayor importancia de las funciones reales mas generales e inconcretas, radique en el hecho de que no se hayan desarrollado y puntualizado.

¿Sería aconsejable regular con detalle la función real de arbitrar $Y$ moderar el regular funcionamiento de las instituciones $y$ establecer el procedimiento a seguir para ejercerla? 
Sinceramente me atrevo a decir que me parece preferible mantener esta facultad del Rey en la forma expresada en la Constitución, pues precisamente en su incertidumbre, ambigüedad y generalidad está la base para ejercerla en formas diversas y con mayor eficacia que si se concentrara en una minuciosa casuística.

Si esa misión se desarrollara puntualmente ¿estaría sujeta al refrendo que requiere la Constitución para los actos del Rey y le priva de una responsabilidad trasladada a quienes ejercen aquél? ¿No podría darse el caso de que ese refrendo hubiera de llevarse a cabo por quien debe ser moderado?

¿Cómo servir de árbitro entre los que tendrían que refrendar la actuación del Monarca en este aspecto para evitar su responsabilidad?

El Profesor Paul Orianne distingue en la función pública tres componentes: Ser, decir y hacer. La función del Rey es esencialmente la de ser. La existencia de la Institución se justifica para lograr el equilibrio nacional, de importancia superior a lo que dice o a lo que hace.

En una Monarquía parlamentaria, donde el Rey reina, pero no gobierna, su papel es verdaderamente difícil. Podríamos decir que su actuación es mas una obra de arte que una función.

La indeterminación convierte en dura la actividad de los reyes en los tiempos modernos. Es áspera y dificil y, en este sentido, Herman Finer se refiere a la necesidad de que los gobernados se indentifiquen míticamente con valores como la virtud y la justicia. $Y$ dice así: "Tienen el sentimiento instintivo de que la vida debe vivirse con estilo elegante o no vale la pena de ser vivida. Un Rey puede servir de ejemplo y de ayuda para que la sociedad adquiera ese estilo. Representa la imagen por la que suspiran y están dispuestos a aceptar el mito viviente".

Tal es la sutileza de estas competencias regias, generales y un tanto gaseosas en una Monarquía parlamentaria, que no es posible encerrarlas en un precepto jurídico ni analizarlas con precisión en un comentario político. Asi puede decirse que la magistratura monárquica es una magistratura de autoridad y de influencia, cuyas advertencias tendrán un valor distinto en diversas situaciones y con arreglo a la propia personalidad del Monarca, a su autoridad y a su ejemplaridad.

El Rey es un símbolo que procura la integración política y social de la comunidad, y esta integración supone tambien una capacidad de 
guía, tanto de la vida social como de la política, lo mismo en el campo de las relaciones internacionales que en el de la vida interna del propio país. De esta manera, la escasez de "potestas» del Rey se compensa con el crecimiento de la "auctoritas».

En la vida diaria, en la conducta permanente; en los despachos con el Presidente del Gobierno, con los Ministros o con las diversas Autoridades; en los discursos que pueden considerarse mas personales, como el Mensaje de Navidad o en el de la Pascua Militar dirigido a las Fuerzas Armadas, el Rey va ejerciendo esa "auctoritas", que es la base del ejercicio de moderar y velar por el funcionamiento regular de las instituciones.

Y esa otra gran obligación, que se combina con una facultad fundamental, como es la de guardar y hacer guardar la Constitución y las Leyes, incluida en la fórmula del juramento -que si el Rey no prestó, sí acató al sancionar nuestra Ley fundamental- le condujo a actuar con carácter excepcional el 23 de febrero de 1981.

En definitiva y por encima de funciones concretas pero siempre compartidas y condicionadas, el papel del Rey es el de constituir en todo momento un modelo para los ciudadanos, porque la Monarquía tiene el objetivo general de colocar a la política en un plano de dignidad y elevación de miras, que esté lejos, muy lejos, de la descomposición $y$ de la indignidad.

Además, el papel del Rey y la eficacia de la Monarquía han de juzgarse en el presente, pero tambien a largo plazo. No se trata tan sólo de salir del paso en un momento determinado o lograr un acierto coyuntural. No es su objetivo obtener el triunfo en unas elecciones. Su labor ha de realizarse con vistas a un futuro lejano.

El Rey no se pertenece a sí mismo. $Y$ esta es una de las servidumbres esenciales de su misión, que reduce, condiciona y limita su vida privada y la de su Familia.

El tacto necesario para acertar a establecer la frontera entre el mantenimiento de una actitud que inspire respeto y la integración en la vida del país, es la base para acomodar la Monarquía actual, democrática y parlamentaria, a un presente que jamás olvide el pasado y encare con esperanza el provenir.

De un país en el que está instaurada la mas tradicional y arraigada de las Monarquías europeas, hemos podido extraer no hace mucho un ejemplo que no debemos olvidar. 
La transición política española no fue sencilla, pero se llevó a cabo con éxito dentro de un clima de colaboración, en que todas las partes hubieron de ceder un poco. La Constitución fue aprobada y lleva 20 años rigiéndonos. La Corona constituyó una pieza fụndamental en el proceso y tambien ha venido funcionando sin problemas. No tratemos de modificar las normas fundamentales para mejorarlas si no es imprescindible. Pero procuremos mejorarnos todos, desde el más elevado al más humilde de los españoles, en el ejercicio de nuestros derechos y en el cumplimiento de nuestros deberes. 